\title{
Olhares sobre o Império: Manuel Alegre e Manoel de Oliveira
}

\section{Gazes over the Empire: Manuel Alegre and Manoel de Oliveira}

Resumo: Em Jornada de África (1989), de Manuel Alegre, e Non, ou a vã glória de mandar (1990), de Manoel de Oliveira, há um explícito diálogo entre o presente da guerra colonial em África - espaço em que se encontram os protagonistas de ambas as obras - e o passado do país, com especial ênfase à batalha de Alcácer Quibir. Pretendemos, ao confrontar o filme e o romance, refletir sobre a trajetória imperialista e o fim do colonialismo português.

Abstract: In Manuel Alegre's Jornada de África (1989), and Manoel de Oliveira's Non, ou a vã glória de mandar (1990), there is an explicit dialogue between the present of the colonial war in Africa - space where the protagonists of both works are placed-and the past of the country, with special emphasis on the battle of Ksar El Kebir. By confronting the movie and the novel, we intend to reflect upon the imperialist path and the end of the Portuguese colonialism.

Palavras-chave: Imperialismo, Colonialismo, Manuel Alegre, Manoel de Oliveira. Keywords: Imperialism, Colonialism, Manuel Alegre, Manoel de Oliveira.

\footnotetext{
* Docente da área de Literatura Portuguesa na Universidade de São Paulo.
} 
Os primeiros anos da década de 1960 são marcados por uma série de conflitos que agita a cena mundial. Período bastante tenso da Guerra Fria (tentativa de derrubada do governo de Fidel Castro, invasão da baía dos Porcos; construção do muro de Berlim; ameaça do fim da moratória dos testes nucleares; crise dos mísseis em Cuba; assassinato do presidente americano John F. Kennedy, por exemplo), é um período também difícil para Portugal.

Nesses anos, o país sofre pressão internacional a favor da autodeterminação dos países africanos sob seu domínio. Em 14 de dezembro de 1960, a Organização das Nações Unidas firma uma resolução tornando ilegal toda a prática colonial, e no dia seguinte, 15 de dezembro, define como colônias os territórios africanos sob dominação portuguesa. ${ }^{1}$ No início de 1961, um levantamento em Angola deflagra o longo período das guerras coloniais, que durará mais de 13 anos e marcará de maneira indelével a história de Portugal do século XX.

Após a Revolução dos Cravos de 25 de abril de 1974, que marca o fim do Estado Novo, como também a derrocada do Portugal Imperial, uma série de obras ficcionais começa a surgir, com o fim da censura, tendo como tema central a revisão da história do país, sobretudo a do último século. Para Maria Lucia Lepecki (1984, p. 13-21), o que caracteriza o romance português pós 25 de abril é a busca pela história e historicidade. Maria Alzira Seixo, por sua vez, considera que uma das tendências da produção portuguesa contemporânea é a de ter o espaço da terra como "centro de radicação do universo romanesco", mesmo quando esta terra está "descentrada", que é o caso, por exemplo, das obras que focalizam a presença portuguesa na África (Seixo, 1986, p. 73). Mais que isso. A revisitação da guerra colonial pela literatura tem sido uma constante desde então. A esse respeito, Roberto Vecchi afirma:

Sobre a literatura portuguesa pós- 25 de Abril muito se escreveu e continua ainda a escrever-se, de maneira por vezes até banal, interrogando-se se exista ou não

\footnotetext{
${ }_{1}^{1}$ Resoluções 1514 e 1542, respectivamente (Cf. Afonso, 1986). Depois da Segunda Guerra Mundial, o governo português passa a sofrer pressão internacional, principalmente por causa das péssimas condições das colônias (servidão, estagnação econômica etc.). Por esse motivo, Salazar promove uma série de mudanças, no início da década de 1950, em relação à política colonial: "A Constituição foi modificada em 1951, acrescentando-se-Ihe as principais disposições do Acto Colonial (...). As palavras "colónia" e "colonial" desapareceram por completo, cedendo o passo a "província ultramarina" e a "ultramarino". A designação "Império" caiu a pouco e pouco no esquecimento." (Marques, 1986, p. 525).
} 
uma obra literária que possa expressar um momento "tão levantado e principal" como foi uma fractura histórica dessa profundidade. Há multíplices razões que motivam o precoce interesse do campo literário para uma "experiência" - e uso aqui o termo no duplo sentido de vivência, mas também etimológica e genealogicamente de proveniência (ex) e passagem (per) - como aquela duma guerra que representa como um quisto - algo de interno e externo, de próprio e impróprio - a complexidade da história da nação-império. Razões vivenciais, culturais, terapêuticas, apotropaicas, antropológicas. Mas uma observação não dispensável é que a literatura da guerra colonial, pelo menos a que surge depois do 25 de Abril, se produz dentro de um questionamento identitário bastante forte, que encontra na literatura o meio de actuação. (2010, p.24)

Parece-nos que dentro dessas perspectivas podem-se enquadrar duas obras de formato distinto, mas que acabam por dialogar entre si. Trata-se do romance Jornada de África, de Manuel Alegre, que veio a lume em 1989 e do filme Non, ou a vã glória de mandar, de Manoel de Oliveira, lançado no ano seguinte. Vindas a público num período bastante próximo, as duas obras se aproximam por tratar da guerra colonial e ao mesmo tempo evocar o passado histórico de seu país, com ênfase na batalha de Alcácer Quibir, e aproximar, cada uma a sua maneira, essas duas "jornadas de África”, que marcaram indiscutivelmente a cultura portuguesa.

No romance, cuja ação se situa a maior parte do tempo em Angola, o entrecho focaliza o início da guerra colonial naquele país, período de recrudescimento da política salazarista, mas no qual, ao mesmo tempo, germinam as organizações que levarão à Revolução dos Cravos e ao consequente fim da mais longa ditadura da Europa Ocidental durante o século XX. Mas não só. Manuel Alegre tece um paralelo entre o protagonista de sua obra, o alferes Sebastião, e um dos personagens mais emblemáticos da história portuguesa, o jovem rei de mesmo nome que desapareceu na batalha de Alcácer Quibir.

Se Jornada de África corresponde à estreia de Manuel Alegre pelos caminhos da prosa literária, por outro lado, vários dos temas que são tratados em seu primeiro romance já estão presentes em sua obra poética. Desde os seus primeiros livros de poesia (ele publica em 1965 Praça da canção e em 1967 O canto e 
as armas) $)^{2}$, até a publicação do primeiro romance, em 1989, inúmeros poemas terão como tema quer a guerra colonial em África, quer o passado ultramarino, quer o fim do período áureo do expansionismo português, marcado pela malsucedida jornada de África, além de, obviamente, focalizarem também os anos difíceis do Estado Novo. Eduardo Lourenço, no prefácio que faz para a edição comemorativa dos 30 anos da estreia literária de Manuel Alegre, e que reúne sua produção poética publicada até então, define o escritor como "poeta-mitólogo por excelência":

Poeta-mitólogo, para começar, da nossa memória portuguesa, alimento primeiro do seu imaginário, não como mera fonte de inspiração ou mimese formal - na sua poesia omnipresente - mas como ideário, como fábula, como epopeia já vivida e convertida em mito. Mas não naquela espécie de mito onde o passado se mente e se desfigura. (Lourenço, 1995, p. VII)

De fato, se a evocação do passado, sobretudo através das referências à figura de D. Sebastião e à batalha de Alcácer Quibir, está presente na poesia de Manuel Alegre, desde sua estreia literária, no entanto, será em Atlântico, de 1981, que o poeta entrecruza, pela primeira vez, a batalha quinhentista e a guerra colonial africana, procedimento que também adotará em seu primeiro romance. Em "Crónica de El-Rei D. Sebastião", presente nesse livro, num franco diálogo com os cronistas que narraram a jornada de África de 1578, o poeta interliga imagens da guerra de Angola à travada por D. Sebastião, como podemos ver nos fragmentos do poema, transcritos abaixo:

O dia pois da infelicíssima batalha quando se ouviu aquela voz: ter ter e o teu jeep explodiu contra um rochedo aquele dia de não mais esquecer quando os tiros soaram em Quipedro e ficámos cercados de metralha aquele dia de morrer morrer

\footnotetext{
${ }^{2}$ Apesar de apreendidos pela censura, esses livros acabam por circular clandestinamente em Portugal.
} 
em que vi o teu corpo sem mortalha no plaino abandonado trespassado por malhas do Império lado a lado.

\section{(...)}

já sem armas na mão e rota a farda aquele dia de não mais esquecer quando os tiros soaram na picada entre Quipedro e Alcácer Quibir aquele dia de morrer morrer.

"E estava El-Rei no corno esquerdo quando João Gomes Cabral foi o primeiro a cair morto. Já o Duque de Aveiro do outro lado o sinal estava esperando. (...) E sendo El-Rei e Aveiro de vencida fazendo grande estrago em sua entrada ouviu-se então não sei por que mau fado aquela voz que há-de ser sempre ouvida: ter ter.

Aquele dia de morrer

Morrer."

(...)

O dia pois da infelicíssima batalha quando se ouviu aquela voz: ter ter e ficamos cercados de metralha. Entre Quipedro e Alcácer Quibir.

Aquele dia de morrer morrer. (Alegre, 1995, p. 421-425)

Como vemos, no poema estão presentes não apenas algumas estrofes que narram o desastre no norte da África como também, em outras, surgem representados os sons das explosões e os barulhos dos tiros e da metralha, enquanto 
lutam e morrem soldados em Quipedro, no interior de Angola. O grito "ter ter" que, segundo as crônicas de Alcácer Quibir, resultou numa recuada do exército liderado pelo rei D. Sebastião, o que acabou por acelerar a derrota dos portugueses (cf. Martins, s.d., p. 55-56), aparece em três estrofes do poema. A esse grito se emparelha o "morrer morrer", que ecoa o "Morrer, sim, mas devagar", que teria sido dito por D. Sebastião, antes de desaparecer nos campos de batalha. A respeito desse entrecruzamento da batalha do passado e a guerra do presente na poesia de Manuel Alegre, Eduardo Lourenço sintetiza que o escritor "como combatente e como poeta adivinha que a pseudo-epopeia da guerra colonial é a antecâmara de um novo Alcácer-Quibir" (p. IX). Essa perspectiva também está presente no filme de Manoel de Oliveira, como veremos adiante.

Jornada de África tem por protagonista um alferes do exército português coIonial, e que, como já dissemos, chama-se Sebastião. $\mathrm{O}$ título do romance retoma o título de uma crônica quinhentista de Jerônimo de Mendonça, que reúne depoimentos de várias testemunhas do desastre de Alcácer Quibir. Vários outros personagens do livro têm nomes que se associam aos personagens que viveram de perto a jornada de D. Sebastião, pois foram companheiros do rei, sobreviventes à batalha.

Assim, vão surgindo nas páginas do romance personagens cujos nomes remetem aos seus homônimos quinhentistas. Portanto, o paralelo que se estabelece, explicitamente, é entre a jornada de 1578, cujo fracasso resultará tanto na perda da autonomia de Portugal, por mais de meio século, como também sepultará o período expansionista lusitano, e essa nova jornada portuguesa por África, que selará o fim do Império colonial português.

A história se passa nos primeiros anos da década de 1960, focalizando o início da guerra colonial em Angola. Contrariamente ao rei do qual herda o nome, que inúmeras crônicas descrevem como o principal responsável pelo desastre de Alcácer Quibir, ao ignorar conselhos desaprovando a jornada à África, o protagonista do romance é opositor ao regime salazarista, opositor à guerra colonial e favorável à autodeterminação das colônias portuguesas ultramarinas. É, como ele próprio se autodefine, um "Sebastião anti-sebastianista e anticolonialista" (Alegre, 1989, p. 132). Entretanto, convocado para o exército português, não deixa de cumprir a missão para a qual é destinado e acaba, por fim, como o seu homônimo, desaparecendo no território africano.

No romance se estabelece um paralelo entre a identidade do narrador - e às 
vezes a do próprio protagonista - com a de Manuel Alegre. A primeira narrativa ficcional do escritor tem como narrador um poeta, que busca uma nova forma de manifestação escrita. Este apresenta-se também como opositor do regime, vive em Coimbra e, mais que isso, é companheiro de Sebastião e frequenta o mesmo círculo de convivência, "são unha e carne", como diz (Alegre, 1989, p. 23).

Quem conhece a biografia do escritor sabe que ele estudou e viveu em Coimbra. Foi, como o protagonista de sua história, convocado para o serviço militar, em 1961, e mobilizado depois para a África no ano seguinte, por sua oposição ao regime político e à guerra colonial. Participou da guerra em Angola e, por conspirar e dirigir uma tentativa de revolta militar, acabou sendo detido pela PIDE e ficou preso durante seis meses, em Luanda, no ano de 1963. Colocado em residência fixa em Coimbra acaba por cair na clandestinidade e exilar-se da pátria, em 1964, retornando para Portugal logo após o 25 de abril.

Com certeza a biografia de Manuel Alegre ajuda a compreender a presença desse tema tão onipresente tanto em sua obra poética como nessa sua primeira narrativa ficcional. Em um dos depoimentos que o escritor faz sobre a sua experiência pessoal em Angola, ele afirma que um dos personagens de seu romance, Domingos da Luta - personagem síntese que representa o Movimento Popular para a Libertação de Angola, o MPLA -, é inspirado em Domingos Pacaça, o Mata-Alferes, conhecido nas crônicas da guerra de Angola por ter se especializado em matar oficiais do exército português.

De fato, Jornada de África se insere no conjunto de obras que revisitam esse período da história portuguesa. Para Eduardo Lourenço, isso vem a sanar um silêncio que a cultura portuguesa pós 25 de abril devota tanto a Salazar como a "tudo que respeita à África":

Durante treze anos de guerra colonial na Guiné, em Angola e em Moçambique, milhares de quadros milicianos, estudantes, médicos, intelectuais foram mobilizados para a última e absurda cruzada contra o independentismo africano. A história desta mobilização - à parte a sua versão em meia dúzia de excelentes romances que mais tarde a irão ficcionar - não está escrita. (Lourenço, 1999, p. 140)

O protagonista do romance de Manuel Alegre considera um paradoxo o silên- 
cio sobre a experiência da guerra. Ele comenta: "Em cada soldado há um mensageiro e um cronista. Quem saberá dar a relação desta Jornada de África? Ela é a crônica que ninguém escreverá" (Alegre, 1989, p. 47).

Se coube inicialmente a poetas e ficcionistas escrever a história dessa última cruzada portuguesa, o cinema também terá um papel importante para sanar essa lacuna a que se refere Eduardo Lourenço. Certamente, Non, ou a vã glória de mandar, de Manoel de Oliveira, cumpre esse papel não apenas por tratar da guerra colonial, mas, sobretudo, por revisitar a trajetória épica de seu país. E essa revisitação se dá num estreito diálogo com a literatura que cantou essas glórias passadas, a começar pelo título e pela epígrafe que abre o filme. Tanto a partícula "Non", como a epígrafe, "Terrível palavra é um non", extraídas do "Sermão da terceira quarta-feira da Quaresma" (1670), de Vieira, como o fragmento da fala do Velho do Restelo (Canto IV, estância 94) antecipam o diálogo com duas figuras incontornáveis quando se trata de refletir sobre o passado épico de Portugal: Luís de Camões e António Vieira. Mais que isso, pois no caso particular de Manoel de Oliveira essas duas referências demonstram mais uma vez a importância que as parcerias literárias têm em sua filmografia.

O fragmento do conhecido verso de Os Lusíadas remete para uma perspectiva que é dissonante ao clima eufórico com o qual o passado português é, de modo geral, retratado na epopeia camoniana, mas que se afina ao tom crítico e desiludido com que Camões reflete, em vários momentos, no mesmo poema, sobre o seu tempo presente, para ele imerso numa apagada e vil tristeza. Ao eleger esse fragmento da fala do Velho do Restelo como componente do título de seu filme, Manoel Oliveira está de antemão e a priori a anunciar seu distanciamento crítico do período e da história portuguesa que serão revisitados em seu filme. $\mathrm{O}$ cineasta claramente opta por fazer uma leitura às avessas. Como ele próprio afirma: "Non consiste em pegar nos Lusíadas do avesso. É o momento em que se desarma a festa" (Oliveira apud Baecque, Parsi, 1999, p. 188).

Numa estrutura que também não deixa de evocar a da epopeia camoniana, a narrativa fílmica de Non, ou a vã glória de mandar tem cenas que focalizam a guerra colonial em África às vésperas da Revolução dos Cravos, intercaladas a cenas feitas a partir de alguns episódios extraídos quer da tradição historiográfica, quer da tradição literária do país.

Recordemos aqui que a narrativa de Os Lusíadas se inicia in media res, com os navegantes portugueses na altura de Moçambique. É através das digressões, 
primeiro de Vasco da Gama narrando ao Rei de Melinde a história dos portugueses, nos cantos III e IV, ou a de Paulo da Gama explicando ao Catual, no canto VIII, quem são as figuras presentes nas bandeiras que enfeitam a nau, que personagens e fatos lendários ou históricos são trazidos para o primeiro plano do poema. No filme de Manoel de Oliveira, por sua vez, algumas dessas histórias que serviram para sedimentar o imaginário épico de Portugal surgem através da evocação de um personagem, o alferes Cabrita, que as narra aos colegas, enquanto o comboio de que fazem parte se desloca pelo interior africano.

Enquanto os soldados são transportados de jipe, eles discutem e questionam a guerra e sua presença em África, falam também por vezes de suas vidas pessoais, mas é, principalmente, através da narração do alferes que a ação acaba por se desenrolar: as histórias por ele narradas trazem para o primeiro plano episódios que acabam por servir de mote para que a trajetória expansionista e imperialista portuguesa seja revisitada e redimensionada.

Em contrapartida, em Os Lusíadas, os navegantes lusitanos estão se deslocando numa viagem que é emblemática de toda a trajetória ultramarina e os feitos dos "barões assinalados" são evocados com a função de justificar o caráter heroico e predestinado dos portugueses na missão de dilatar a fé e o império, como se antecipa num dos primeiros versos do épico camoniano. Por esse motivo, por narrar esses feitos, não apenas os heróis do passado são retratados em luta contra os adversários à soberania do país, mas também os marinheiros comandados por Vasco da Gama precisam lutar para chegar ao seu destino. Já em Non, ou a vã glória de mandar, a deslocação dos soldados se caracteriza, na maioria das cenas, justamente pela falta de ação, que se concentra nos feitos contados pelo narrador; é apenas numa das cenas finais que eles entram em luta e ocorre o embate com os africanos. De fato, a "recapitulação do passado em grande escala elide toda a questão da colonização da África", que acaba por ser recalcada no filme (Xavier, 2013, p. 190).

Se toda batalha travada em Os Lusíadas, tanto as dos heróis do passado como as de Vasco e seus marinheiros, parece se justificar por resultar numa conquista maior, a ultramarina, ponto máximo da façanha dos portugueses na história ocidental, no filme de Manoel de Oliveira vários soldados consideram que a guerra que travam em África é injusta, ou seja, colocam em questão o discurso ideológico do Estado que defende a presença portuguesa no Ultramar e a permanência das colônias. 
Todos esses questionamentos surgem a partir da digressão ao passado motivada pela referência a Viriato, após um dos soldados afirmar que o fato de Portugal manter a guerra e recusar a independência das colônias africanas faz com que o país acabe ficando sem apoio internacional: "os portugueses estão sós contra o mundo". Viriato é então evocado como o herói - forte e magnânimo - que lutou contra os romanos, retardando a ocupação e assimilação da sua aldeia pelo império estrangeiro.

"Nossa pátria é a nossa aldeia", afirma um dos personagens. Entretanto, como explicita o alferes, o contexto agora é outro: são os nativos africanos que resistem ao colonizador, que lutam para defender a sua aldeia-pátria. Nesse confronto, os portugueses são os adversários à soberania de um povo que luta por sua independência e autonomia.

Ao optar por iniciar a revisitação do passado com a história de Viriato, Manoel de Oliveira parece se colocar em sintonia com toda uma tradição da historiografia portuguesa, herdada do século XVI, que elege o pastor/guerreiro como símbolo da "resistência autóctone contra a ocupação romana", e o eleva à condição de "herói nacional", como a ele se refere o historiador José Mattoso (1993, p. 215); tradição que também encontrará ecos na literatura desde Camões a Fernando Pessoa.

Entretanto, ao eleger Viriato para rememorar o passado, o cineasta retoma um dos heróis da mitologia lusitana não para reforçar a imagem heroica dos portugueses em sua luta pela autonomia, como habitualmente ele é representado, mas para colocar em xeque a anacrônica tentativa do governo português de manter o projeto imperialista já quase no último quartel do século $X X$.

Outro ponto de ligação entre o filme e Os Lusíadas aparece quando o alferes Cabrita relaciona as dificuldades enfrentadas pelos portugueses em seus planos de expandir o território ou criar um império ibérico a um desígnio dos deuses. Ao narrar, por exemplo, a morte de Viriato, Cabrita afirma que a ação do herói foi condenada pelos deuses, já que, em sua interpretação, o "patriota trágico" "jogou o destino de um povo antes do seu tempo próprio". Ao se referir aos limites geográficos portugueses, o mar e a Espanha, também considera que são limites impostos pelos deuses.

No poema camoniano, as adversidades encontradas pelos marinheiros durante a viagem têm a intervenção dos Deuses: Baco tenta impedi-los de chegar ao destino, e Vênus os protege, procurando contornar os percalços causados pelas 
ciladas de Baco. Ou seja, as ações dos argonautas portugueses acabam limitadas por elementos advindos de forças que eles desconhecem. No filme, por sua vez, a evocação às divindades mitológicas presentifica-se com uma cena inspirada no episódio camoniano da Ilha dos Amores, e mostra o quanto Manoel de Oliveira reforça o intertexto com a épica quinhentista.

Obviamente, se o diálogo com Camões é fundamental para refletirmos sobre a estrutura do filme, as escolhas de Oliveira não se restringem ao intertexto com a obra do poeta. Nas cenas que atualizam as histórias do passado, vários dos personagens são representados pelos mesmos atores que interpretam os soldados. Essa estratégia adotada pelo cineasta acaba por ter a função de aproximar criticamente, aos olhos do espectador, passado e presente. Mais que isso, possibilita que se reflita sobre o sonho imperialista, parcialmente realizado no passado, e seus estertores, simbolicamente representado no filme pela bataIha travada pelos soldados portugueses, da qual sai gravemente ferido o alferes Cabrita. De fato, são duas batalhas que se entrecruzam: a de Alcácer Quibir, de agosto de 1578, e a que ocorre quase quatro séculos depois, em abril de 1974, já que a última cena do filme é a do médico que cuidou do alferes Cabrita preenchendo os motivos do óbito e datando dia e hora do falecimento do soldado: 25 de abril de 1974.

Se Manuel Alegre aproxima os dois tempos ao dar o mesmo nome dos personagens históricos que estiveram presentes na batalha de Alcácer Quibir aos personagens de seu romance, a saída encontrada pelo cineasta para alcançar efeito similar é utilizar os mesmos atores que vivem a ação do presente para representar os heróis do passado. Aliás, durante quase todo o filme, a movimentação dos soldados é caracterizada justamente pela falta de ação, já que eles se deslocam pelo interior da África rememorando os feitos de vários personagens do passado pátrio, sendo estes, de fato, os agentes da maioria das ações que o espectador assiste.

Entre os heróis revisitados no filme, o último é D. Sebastião e a malfadada jornada quinhentista. $\mathrm{O}$ alferes Cabrita lembra que alguns conselheiros do rei o consideravam louco, e que sua loucura arrastaria o reino para a perdição. Recorda, ainda, que é atribuída ao rei, ao reconhecer a desvantagem numérica do exército português, a frase: "Morrer, sim, mas devagar", que teria dito ao ser aconselhado a se retirar para tentar preservar sua vida. A seguir às imagens da batalha de Alcácer Quibir, sucede a batalha da guerra colonial, em que sai mor- 
talmente ferido o alferes-narrador.

Na última sequência do filme, o nosso olhar acompanha a imagem registrada pela câmara que percorre, lentamente, os leitos de um hospital militar, mostrando soldados mutilados até se fixar na imagem no alferes Cabrita, quase irreconhecível devido aos ferimentos. Talvez o episódio do romance que mais se aproxima dessa imagem seja o que narra a visita que Sebastião faz a um amigo, que se encontra ferido também num hospital militar. Sua reação diante dos inúmeros mutilados pela guerra é de mal-estar e revolta. A partir daí, através das reflexões do protagonista do romance, temos uma releitura crítica e amarga da propaganda salazarista de estímulo aos combatentes de África: "Para Angola e em força"; "Coxos, manetas, paraplégicos. O resto ficou nas picadas, Angola é nossa, venham ver, há bocados de Portugal florindo algures no mato, sangue e merda, duarte de almeida é o nosso nome, Para Angola e em força, braços, pernas, mãos" (Alegre, 1989, p. 169).

Se o desabafo de Sebastião não deixa dúvida nenhuma em relação à crítica que há no romance à guerra colonial, Oliveira se servirá de imagens para alcançar o mesmo fim: entre os delírios do alferes Cabrita, aparece el-rei D. Sebastião, segurando a lâmina da própria espada, e de suas mãos verte sangue. A imagem é bastante explícita. O preço para construir um grande império, ou Quinto Império, (as ideias messiânicas de Bandarra e de Vieira também são discutidas pelos personagens), é bastante caro.

Se Camões criou um Velho do Restelo a interrogar, "alevantando" a voz, o custo do expansionismo lusíada - imagem evocada no título do filme, Manoel de Oliveira também cria o seu. Em Non, ou a vã glória de mandar, no campo devastado coberto de corpos de soldados portugueses mortos em Alcácer Quibir, levanta-se um velho que estivera presente nas cenas da batalha quinhentista e que questiona, em altos brados, antes de suicidar-se com a própria espada, o alto preço pago pela aventura africana. O seu discurso retoma o "Non" do título e da epígrafe do filme:

Terrível palavra é um non: não tem direito nem avesso, por qualquer lado que o tomeis, sempre soa e diz o mesmo. Lede-o do princípio para o fim, ou do fim para o princípio, sempre é um non. Quando a vara de Moisés se converteu naquela serpente tão feroz, que fugia dela por que o não mordesse; disse-lhe Deus que a tomasse ao revés, e logo perdeu a figura, a ferocidade, a peçonha. $\mathrm{O}$ non não 
é assim: por qualquer parte que o tomeis é sempre serpente, sempre morde, sempre fere, sempre leva o veneno consigo. (Vieira, 2001, p. 250)

Composto por um excerto retirado do "Sermão da Terceira Quarta-feira da Quaresma", do padre Antonio Vieira, o desabafo desse personagem, quase no final do filme, parece condensar a crítica do cineasta aos equivocados caminhos tomados pelos portugueses na tentativa de criar e manter um Império colonial. Em Jornada de África, de Manuel Alegre, por sua vez, também no final do romance, o protagonista deixa o seu testemunho crítico sobre a guerra colonial e o sonho imperialista. No último encontro que tem com o Poeta, logo antes de seu desaparecimento no campo de batalha, Sebastião entrega ao amigo "uma folha de papel quadriculado", a que chama de "esta prosa", com sua mensagem de protesto:

Sentado no jipe, a caminho de Quipedro, o Poeta lê, perplexo, a mensagem de Sebastião:

"Talvez o Quinto Império seja afinal o fim de todos os impérios. O Grande Império do Avesso, o Anti-Império. E talvez seja esse o único sentido possível desta guerra: fechar o ciclo. Talvez tenhamos de nos perder aqui para chegar finalmente ao porto por achar: dentro de nós. Talvez tenhamos de não ser para podermos voltar a ser. Há outro Portugal, não este. E sinto que tinha de se passar por aqui para o encontrar. Não sei se passado, não sei se futuro. Não sei se fim ou se princípio. Sei que sou deste país: um país que já foi, um país que ainda não é.

É por ele que me apetece dar de novo Santiago." (Alegre, 1989, p. 231)

Por esse país, cuja identidade passa por uma crise com a iminência da perda do Império, o comprometido protagonista do romance vai à luta: Ihe "apetece dar de novo Santiago"3, o que o homem, o político, o poeta Manuel Alegre nunca deixou de fazer em sua trajetória pública.

Já Manoel de Oliveira, em Non, ou a vã glória de mandar, vai por vereda similar ao retomar Luís de Camões e António Vieira ao revés. Se cada um desses escritores, no seu século e a sua maneira, sonhou, de certa forma, com um quin-

\footnotetext{
${ }^{3}$ Manuel Alegre redimensiona a expressão medieval utilizada durante as guerras contra os mouros, quando se invocava o nome de Santiago.
} 
to império português que suplantasse "assírios, persas, gregos e romanos" (Os Lusíadas, Canto I, 24) e contribuiu para a mitificação de Portugal, Manoel de Oliveira vai na contramão dessa tradição: o seu balanço da identidade da sociedade portuguesa após a revolução dos Cravos parece apontar para a necessidade de romper com esse círculo, com essa serpente que sempre morde, sempre fere, sempre leva o veneno consigo. Afinal, nas duas principais épocas retratadas no filme, em 4 de agosto de 1578 e 25 de abril de 1974, a insistência em manter o império colonial é associada à loucura, que arrasta toda a pátria para a perdição.

Manuel Alegre e Manoel de Oliveira não se eximem de indagar qual o lugar de Portugal, após a perda do Império. Suas obras revelam que não é possível fazer esse balanço sem revisitar os mitos do passado. Mais que isso, não dá para refletir sobre a identidade da sociedade portuguesa pós Revolução dos Cravos sem evocar e redimensionar uma certa visão mítica do destino português - a expressão, obviamente, é de Eduardo Lourenço (1978). Cineasta e poeta/romancista, cada um, a sua maneira, denunciam que há mais de quinhentos anos os portugueses têm pagado caro por essa aventura. Alevantam a voz, como novos velhos do Restelo, afirmando a incondicional premência de dar um basta, dizer um não à glória de mandar, à vã cobiça.

\section{Referências Bibliográficas}

AFONSO, Aniceto. A Guerra Colonial. In: MEDINA, João. História Contemporânea de Portugal. Lisboa: Amigos do Livro, 1986.

ALEGRE, Manuel. Jornada de África (Romance de Amor e Morte do Alferes Sebastião). Lisboa: Publicações Dom Quixote, 1989.

. Manuel Alegre - 30 anos de poesia. Lisboa: Dom Quixote, 1995.

BAECQUE, Antoine; PARSI, Jacques. Conversas com Manoel de Oliveira. Porto: Campo das Letras, 1999.

CAMÕES, Luís de. Os Lusíadas. Rio de Janeiro: Biblioteca do Exército, 1980.

LEPECKI, Maria Lúcia. O Romance Português Contemporâneo na Busca da História e Historicidade. Actes du Colloque: Le roman portugais contemporain. Paris: Fondation Calouste Gulbenkian, 1984, p.13-21.

LOURENÇO, Eduardo. O Labirinto da Saudade. Lisboa: Dom Quixote, 1978.

. Manuel Alegre ou a nostalgia da epopeia. Manuel Alegre - 30 anos de poesia. Lisboa: Dom Quixote, 1995. p. III-XVI. 
. Mitologia da Saudade. São Paulo: Companhia das Letras, 1999.

MARQUES, A. H. de Oliveira. História de Portugal. V.3. 3. ed. Lisboa: Palas Editores, 1986.

MARTINS, Oliveira. História de Portugal. 2. v. Lisboa: Europa-América, s.d.

MATTOSO. José. História de Portugal. Antes de Portugal. V. 1. Lisboa: Estampa, 1993.

OLIVEIRA, Manoel. Non, ou a vã glória de mandar. Portugal, França, Espanha. Texto histórico: João Marques. Diálogos: Manoel de Oliveira. 1990.

PESSOA, Fernando. Obra Poética. 9. ed. Rio de Janeiro: Nova Aguilar, 1983.

SEIXO, Maria Alzira. A Palavra do Romance; ensaios de genologia e análise. Lisboa: Livros Horizonte, 1986.

VECCHI, Roberto. Excepção Atlântica. Pensar a Literatura da Guerra Colonial. Porto: Edições Afrontamento, 2010.

VIEIRA, Antonio. Sermões. Tomo I. (organização e introdução Alcir Pécora). São Paulo: Hedra, 2001.

XAVIER, Ismail. A morte do alferes Cabrita e a Paixão Portuguesa. In: FERREIRA, Carolin Overhoff. (Org.). Manoel Oliveira: novas perspectivas sobre sua obra. São Paulo: Editora FAP-UNIFESP, 2013, p.183-211. 